\title{
Muonium and Water in Histidine Amino Acid
}

\section{A. D. Pant}

\section{Journal of Nepal Physical Society}

Volume 7, Issue 2, June 2021

ISSN : 2392-473X (Print), 2738-9537 (Online)

\section{Editors:}

Dr. Binod Adhikari

Dr. Bhawani Joshi

Dr. Manoj Kumar Yadav

Dr. Krishna Rai

Dr. Rajendra Prasad Adhikari

Mr. Kiran Pudasainee

JNPS, 7 (2), 65-68 (2021)

DOI: https://doi.org/10.3126/jnphyssoc.v7i2.38624

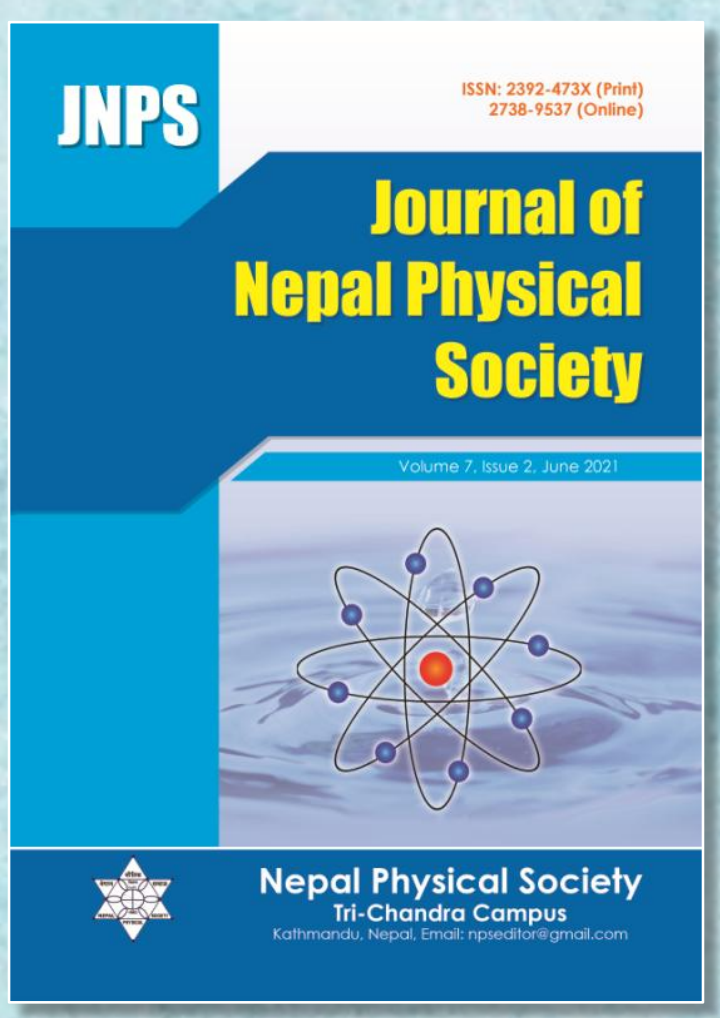

Published by:

Nepal Physical Society

P.O. Box: 2934

Tri-Chandra Campus

Kathmandu, Nepal

Email:nps.editor@gmail.com 


\title{
Muonium and Water in Histidine Amino Acid
}

\author{
A. D. Pant \\ Institute of Materials Structure Science, Muon Science Laboratory \\ High Energy Accelerator Research Organization (KEK), \\ 1-1 Oho, Tsukuba, Ibaraki 305-0801, Japan \\ Corresponding Email: pant@ post.kek.jp
}

Received: 5 April, 2021; Revised: 19 May, 2021; Accepted: 29 June, 2021

\begin{abstract}
In order to apply muon spin rotation and relaxation method for study of life sciences like electron transfer process, detection of molecular concentration, photosynthesis process, etc., theoretical study to understand the stopping sites of muon and its charge species in the macromolecules is necessary. In the systematic theoretical study to know the behaviour of muon and muonium in water hydrated biological macromolecules like protein and DNA through the first-principles approach, the behaviour of a water molecule in the presence of muonium in histidine amino acid with extended main chain is presented here. The sites of a water molecule and a muonium in histidine amino acid are estimated. Two possible sites with potential energy $0.3 \mathrm{eV}$ (approximately) for water molecule in the optimized structure of muonium in extended main chain histidine were estimated. Water in the sites is expected to contribute to enhance the intra- and inter-chain electron transfer in the system as reported experimentally.
\end{abstract}

Keywords: Muon spin rotation and relaxation, Muonium, Histidine, Water.

\section{INTRODUCTION}

Muon spin rotation and relaxation $(\mu \mathrm{SR})$ technique is being popular for study of life, materials, nuclear physics, elementary, new physics, etc. Since discovery of muon by Neddermeyer and Anderson [1] in 1937, and first $\mu$ SR experiment by Garwin [2], this method has been used in wide varieties of physics, chemistry, and biology. We have been using $\mu S R$ for study of life sciences especially electron transfer in proteins [3] and DNA [4], detection of oxygen in tissue [5], and photosynthesis process. In order to understand the stopping site of muon in the sample, theoretical study like first-principles calculation is necessary. For this purpose, in addition to experiment, systematic theoretical study starting from the constituents of proteins [6] has been performing which supports the experimental results and deepen the knowledge of behaviour of muon in the materials.

Muon is spin-half leptonic particle. It is like a light proton. The gyromagnetic ratio of muon is three times higher than that of proton which makes it more sensitive to materials. The bound state of a muon and an electron is called muonium $(\mathrm{Mu})$ which is like a light isotope of $\mathrm{H}$ with similar chemical behaviour. Naturally, muon is available in cosmic ray, and also can generate in accelerator facilities. For high intensity and tuneable energy, we have used the muon beam available in accelerator laboratories. Because of its two characteristics properties - (a) asymmetric decay into positron and (b) $100 \%$ polarization, it acts as an exotic tool for life and materials study. In $\mu$ SR technique, implanted muon to sample decays into positron which is collected by detectors around the sample. Based on polarization of muon, we can understand the local electronic and dynamic behaviour of materials in which muon stops. The details about $\mu$ SR technique is available elsewhere [7].

We have studied electron transfer in cytochrome c protein $[3,8,9]$. The temperature and hydration dependent study shows the electron transfer depends on those parameters/environments [8]. The 
dimensionality of electron transfer also depends on amount of water contents in the sample that we called water hydration. It is also reported that the water hydration accelerates the electron transfer rate $[10,11]$. In our study at different water hydration (less than 5\% and around 20\%), both inter-chain and intra-chain electron movement were found enhanced by adding the water molecules in the cytochrome $\mathrm{c}$ protein $[8,9]$. To understand such process, we have started systematic study from muon and muonium behaviour in amino acids towards whole protein. First-of-all, we found that, in theoretical calculation the potential energy for muon and $\mathrm{Mu}$ depends on the passivation of the computational model. After testing the various model of termination of main chain of amino acids, it is found that the termination of main chain by peptide like bond is more realistic to biological system $[6,12,13]$. Using such model, the stopping site of muon and muonium in amino acids (histidine [12, 13], glycine, triglycine[6], methionine [13], tyrosine, tryptophan and phenylaniline [14]) have been studied. Here, the behaviour of a water molecule in the muonium and histidine amino acid using density functional theory is presented.

\section{METHOD}

The theoretical calculations were performed using hybrid density function B3LYP with the basis sets 6-31G(d) in Gaussian 09 set of programs [15]. In our previous studies, we have optimized the different systems for suitable model and basis set

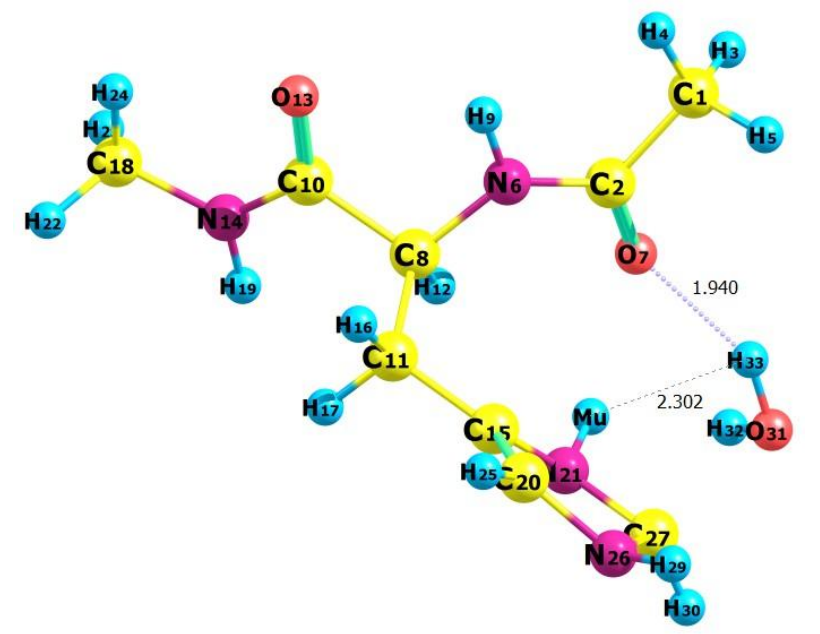

[6, 12-14]. In the B3LYP level of calculation, both gradient and exchange correlations are included. The basis set 6-31G(d) describes well the orbitals of first and second rows elements. Initial charge state of muon was taken as Mu which is chemically similar to $\mathrm{H}$ atom. The potential energy (PE) surface for a water around the possible electronegative sites (in many cases $\mathrm{N}$ and $\mathrm{O}$ ) and around $\mathrm{C}$ in previously optimized muonium histidine extended main chain system were tested [13]. The search of stopping sites of water was performed through optimization of the energy. The optimization was confirmed by checking electronic energy $(E)$, frequencies and convergence criteria in each calculation. The water molecule was left as relax however the histidine with muonium was kept fixed from ref. 13 [13]. The potential energy for water in different positions was calculated as,
$\mathrm{PE}=\mathrm{E}\left(\right.$ Histidine $\left.+\mathrm{Mu}+\mathrm{H}_{2} \mathrm{O}\right)-[\mathrm{E}($ Histidine + $\left.\mathrm{Mu})+\mathrm{E}\left(\mathrm{H}_{2} \mathrm{O}\right)\right]$

The $\mathrm{E}$ (Histidine $+\mathrm{Mu}+\mathrm{H}_{2} \mathrm{O}$ ) is total optimized energy of the system (Histidine $+\mathrm{Mu}+\mathrm{H}_{2} \mathrm{O}$ ) and so on.

\section{RESULTS AND DISCUSSION}

The optimized structure of a water molecule in different possible sites were calculated. The potential energy for the water in two possible sites - water stopped in the vicinity of main chain and aromatic side chain where $\mathrm{Mu}$ stopped (Fig. 1 (left)), and near the oxygen of main chain (Fig. 1 (right)) are presented in table 1 .

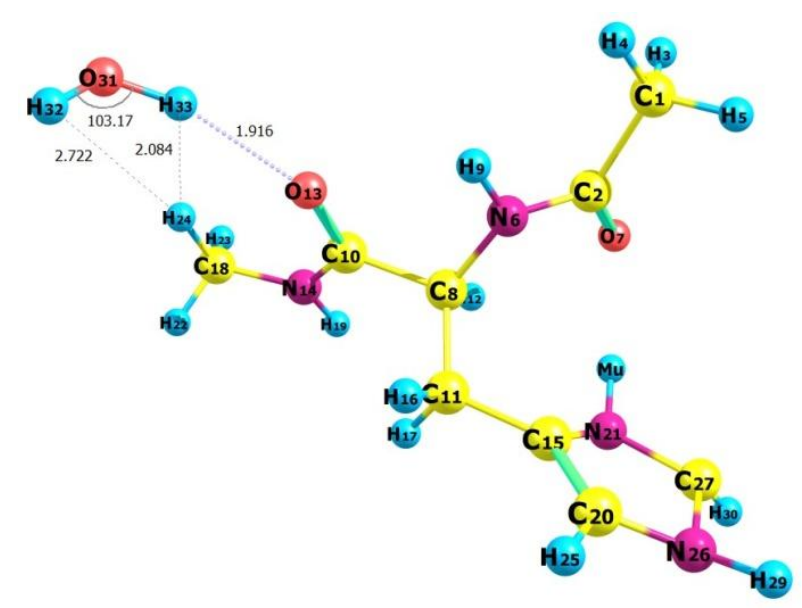

Fig. 1: Optimized structure of muonium and a water molecule in histidine. Left figure shows the optimization of a water molecule in the vicinity of $\mathrm{O}_{7}$ and $\mathrm{Mu}$ stopped near $\mathrm{N}_{21}$ (nitrogen of aromatic side ring), and right figure shows the stopping of the water molecule near $\mathrm{O}_{13}$ of extended main chain. 
Table 1: Potential energy for water in two possible sites in histidine with Mu system.

\begin{tabular}{lc}
\hline Stopping sites & Potential energy (eV) \\
\hline Water stopped in vicinity of aromatic side chain and main chain (Fig. & 0.30 \\
$\begin{array}{l}1, \text { left) } \\
\text { Water stopped in main chain (around } \mathrm{O}_{13} \text { ) (Fig. 1, right) }\end{array}$ & 0.37 \\
\hline
\end{tabular}

When the water molecule stopped in the vicinity of $\mathrm{Mu}$ in aromatic side chain and oxygen $\left(\mathrm{O}_{7}\right)$ of main chain, one $\mathrm{H}\left(\mathrm{H}_{33}\right.$ in left figure) of water remain at $1.94 \AA$ apart (like hydrogen bonding) from the oxygen with potential energy $0.30 \mathrm{eV}$. In second possible site - water near $\mathrm{O}\left(\mathrm{O}_{13}\right.$ Fig. 1, right), one of hydrogens of the water also remains at $1.916 \AA$ distance from oxygen with potential energy 0.37 $\mathrm{eV}$. As reported by Lin et al [10] and Hayashi et al [11], water molecule behaves as tunnel to accelerate electron transfer process. In our $\mu \mathrm{SR}$ study [8], we also found the water hydration enhanced the intra-chain and inter-chain electron transfer by $70 \%$ and $30 \%$, respectively, when water hydration increased from 5\% to $20 \%$ [8]. As found in present work, the water stopped in both sites may contribute for transfer of electron from a chain to another or from main chain to side chain. Further study of addition of more water molecules as in experimental sample will help to understand the measured result.

Since the limitation of conventional muon to apply in single crystal of protein, we have been developing the ultra-slow muon microscopy at materials and life science facility, Japan Proton Accelerator Research Complex (J-PARC) [16-19]. Using the muon micro beam of tunable energy to stop at desired depth of sample and adjustable beam size $(\sim \mu \mathrm{m})$, single crystal protein, its functional properties, etc. will be studied.

\section{CONCLUSION}

Behavior of a water molecule in optimized structure of muonium stopped in extended main chain histidine has been studied using the first-principles calculations. It is found that there are two possible sites for a water molecule in the system with potential energy $0.3 \mathrm{eV}$ approximately. Both sites are expected to play significant role to enhance the electron transfer process in the protein as observed in hydration dependent experimental result. Further theoretical study towards whole protein system with first hydration shell will deepen the understanding and support the muon experimental data.

\section{ACKNOWLEDGEMENT}

This work was supported by Grant-in-Aid for Scientific Research of the Ministry of Education, Culture, Sports, Science and Technology (MEXT), Japan, (Grant Number: 21K15583, "Applications of muon in cancer research").

\section{REFERENCES}

[1] Neddermeyer, S. H.; and Anderson, C. D. Note on the Nature of Cosmic-Ray Particles, Physical Review, 51: 884-886 (1937).

[2] Garwin, R. L.; Lederman, L. M.; and Weinrich, M. Observations of the Failure of Conservation of Parity and Charge Conjugation in Meson Decays: the Magnetic Moment of the Free Muon, Physical Review, 105: 1415-1417 (1957).

[3] Nagamine, K.; Pratt, F.L.; Ohira, S.; Watanabe, I.; Ishida, K.; Nakamura, S. N.; and Matsuzaki, T. Intra- and inter-molecular electron transfer in cytochrome $\mathrm{c}$ and myoglobin observed by the muon spin relaxation method, Physica B, 289: 631 (2000).

[4] Torikai, E.; Hori, H.; Hirose, E.; and Nagamine, $\mathrm{K}$. Electron transfer in DNA probed by the muon labelling method: A new interpretation, Physica B: Condensed Matter, 374-375: 441-443 (2006).

[5] Pant, A. D.; Nagamine, K.; Shiraki, I.; Torikai, E.; Shimomura, K.; Pratt, F. L.; Ariga, H.; Ishida, K.; and Schultz, J. S. Muonium response to oxygen content in biological aqueous solutions for cancer research, Journal of Physics: Conference Series, 551: 012043 (2014).

[6] Pant, A. D.; Sugawara, Y.; Nakanishi, H.; Torikai, E.; Higemoto, W.; Shimomura, K.; and Nagamine, K. Theoretical Calculations of Charge States and Stopping Sites of Muons in Glycine and Triglycine, JPS Conf. Proc., 21: 011038 (2018).

[7] Nagamine, K. Introductory Muon Science, Cambridge University Press, Cambridge, UK (2007).

[8] Pant, A. D.; Sugawara, Y.; Yanagihara, I.; Khanal, G. P.; Shiraki, I.; Higemoto, W.; Shimomura, K.; Ishida, K.; Pratt, F. L.; Torikai, E.; and Nagamine, K. Hydration Effect on Electron Transfer in Cytochrome c Monitored by uSR, JPS Conf. Proc., 8: 033007 (2015). 
[9] Sugawara, Y.; Pant, A. D.; Higemoto, W.; Shimomura, K.; Torikai, E.; and Nagamine, K. Hydration Effects on Electron Transfer in Biological Systems Studied by muSR, JPS Conf. Proc. , 2: 010310-010311 (2014).

[10] Lin, J.; Balabin, I. A.; and Beratan, D. N. The nature of aqueous tunneling pathways between electron-transfer proteins, Science, 310: 13111313 (2005).

[11] Tomoyuki Hayashi; and Stuchebrukhov, A. A. Electron tunneling in respiratory complex I, Proc. Natl. Acad. Sci., 107: 19157 (2010).

[12] Pant, A. D.; Sugawara, Y.; Torikai, E.; Higemoto, W.; Shimomura, K.; and Nagamine, K. A FirstPrinciples Study of Muonium in Histidine, JPS Conf. Proc., 25: 011012 (2019).

[13] Pant, A. D.; Sugawara, Y.; Torikai, E.; Higemoto, W.; Shimomura, K.; and Nagamine, K. Muon and Muonium in Cytochrome c: DFT Calculations on Histidine and Methionine, JPS Conf. Proc., 25: 011013 (2019).

[14] Pant, A. D. Muonium behavior in amino acids (tyrosine, tryptophan and phenylalanine), Himalayan Physics, 8: 88-92 (2019).

[15] Frisch, M. J.; Trucks, G. W.; Schlegel, H. B.; Scuseria, G. E.; Robb, M. A.; Cheeseman, J. R.; Scalmani, G.; Barone, V.; Mennucci, B.; Petersson, G. A.; Nakatsuji, H.; Caricato, M.; Li, X.; Hratchian, H. P.; Izmaylov, A. F.; Bloino, J.; Zheng, G.; Sonnenberg, J. L.; Hada, M.; Ehara, M.; Toyota, K.; Fukuda, R.; Hasegawa, J.; Ishida, M.; Nakajima, T.; Honda, Y.; Kitao, O.; Nakai, H.; Vreven, T.; Montgomery, J. A.; Ogliaro, F.; Bearpark, M.; Heyd, J. J.; Brothers, E.; Kudin, K. N.; Staroverov, V. N.; Kobayashi, R.; Normand, J.; Raghavachari, K.; Rendell, A.; Burant, J. C.; Iyengar, S. S.; Tomasi, J.; Cossi, M.; Rega, N.; Millam, J. M.; Klene, M.; Knox, J. E.; Cross, J. B.; Bakken, V.; Adamo, C.; Jaramillo, J.; Gomperts, R.; Stratmann, R. E.; Yazyev, O.; Austin, A. J.; Cammi, R.; Pomelli, C.; Ochterski, J. W.; Martin, R. L.; Morokuma, K.; Zakrzewski, V. G.; Voth, G. A.; Salvador, P.; Dannenberg, J. J.; Dapprich, S.; Daniels, A. D.; Farkas, Ö.; Foresman, J. B.; Ortiz, J. V.; Cioslowski, J.; and Fox, D. J.; Gaussian 09, Revision C.01, Gaussian Inc. Wallingford CT, (2009).

[16] Miyake, Y.; Shimomura, K.; Kawamura, N.; Koda, A.; Strasser, P.; Kojima, K. M.; Fujimori, H.; Makimura, S.; Ikedo, Y.; Kobayashi, Y.; Nakamura, J.; Oishi, Y.; Takeshita, S.; Adachi, T.; Pant, A. D.; Okabe, H.; Matoba, S.; Tampo, M.; Hiraishi, M.; Hamada, K.; Doiuchi, S.; Higemoto, W.; Ito, T. U.; and Kadono, R. JPARC Muon Facility, MUSE, JPS Conf. Proc., 21: 011054 (2018).

[17] Pant, A. D.; Adachi, T.; Strasser, P.; Ikedo, Y.; Oishi, Y.; Nakamura, J.; Higemoto, W.;
Shimomura, K.; Kadono, R.; Miyake, Y.; and Torikai, E. Characterization and optimization of ultra slow muon beam at J-PARC/MUSE: A simulation study, Nuclear Instruments and Methods in Physics Research Section A: Accelerators, Spectrometers, Detectors and Associated Equipment, 929: 129-133 (2019).

[18] Pant, A. D.; Adachi, T.; Ikedo, Y.; Oishi, Y.; Nakamura, J.; Strasser, P.; Kojima, K.; Makimura, S.; Kawamura, N.; Koda, A.; Ito, T.; Higemoto, W.; Shimomura, K.; Kadono, R.; Miyake, Y.; and Torikai, E. Transportation of Ultra Slow Muon on U-line, MLF, J-PARC, JPS Conf. Proc., 21: 011060 (2018).

[19] Pant, A. D. Conventional to slow muon microscopy - a review, Bibechana, 17: 139-145 (2020). 